\title{
Putting the Lasts First: The Case for Community- Focused and Peer-Managed NGO Accountability Mechanisms
}

\author{
Niaz Murtaza
}

Published online: 24 February 2011

(C) The Author(s) 2011. This article is published with open access at Springerlink.com

\begin{abstract}
The calls for NGO accountability have grown louder in recent years, some based on genuine concerns to help improve their performance and others on a desire to muffle their advocacy activities. Using a comprehensive analytical framework, this article finds that current accountability approaches prioritize accountability to boards and donors and give weak accountability to communities despite strong NGO rhetoric to the contrary. The article recommends the development of accountability mechanisms managed by NGO coordination bodies and focused primarily on accountability to communities to improve NGO performance and protect them from politically motivated attacks.
\end{abstract}

Résumé Les appels à la responsabilité des ONG se sont faits plus pressants ces dernières années. Certains s'appuient sur une volonté authentique de les aider à améliorer leur efficacité, et d'autres sur le désir d'étouffer leurs activités de soutien. À travers une démarche analytique complète, cet article démontre que les approches actuelles privilégient la responsabilité des ONG face aux commissions et aux donateurs et leur attribuent une faible responsabilité devant les communautés, en dépit des démentis formels des ONG. Cet article recommande le développement de mécanismes de responsabilité gérés par les organismes de coordination des ONG et principalement axés sur la responsabilité face aux communautés, afin d'améliorer l'efficacité des ONG et de les protéger des attaques à visée politique.

Niaz Murtaza is a Research Associate at the Mack Center for Non-Profit Management, University of California with research interests focused on NGO accountability, aid effectiveness and sustainable development issues.

N. Murtaza $(\bowtie)$

Mack Center for Non-Profit Management, University of California, 945 Ohlone Ave \# 961, Berkeley, Albany, CA 94706, USA

e-mail: murtazaniaz@yahoo.com 
Zusammenfassung Die Forderungen nach einer Rechenschaftspflicht nichtstaatlicher Organisationen haben in den letzten Jahren zugenommen, wobei einige auf dem aufrichtigen Anliegen beruhen, zu ihrer Leistungsverbesserung beizutragen, während andere durch den Wunsch geleitet werden, ihre Lobbyaktivitäten einzuschränken. Mit Hilfe eines umfassenden analytischen Systems kommt dieser Beitrag zu dem Ergebnis, dass die gegenwärtigen Ansätze die Rechenschaftspflicht gegenüber Vorständen und Spendern prioritisieren und eine nur geringe Rechenschaftspflicht gegenüber den Gemeinschaften vorsehen, auch wenn die nichtstaatlichen Organisationen mit starker Rhetorik dagegenhalten. Der Beitrag empfiehlt die Entwicklung von Rechenschaftsmechanismen, die von den Koordinierungsgremien der nichtstaatlichen Organisationen verwaltet werden und sich vornehmlich auf die Rechenschaftspflicht gegenüber den Gemeinschaften konzentrieren, um so die Leistung der nicht-staatlichen Organisationen zu verbessern und sie vor politisch motivierten Übergriffen zu schützen,

Resumen En los últimos años cada vez son más las voces que reclaman a las ONG la presentación de sus cuentas, algunas basadas en auténticas preocupaciones por ayudar a mejorar sus resultados y otras desde el deseo de amortiguar sus actividades de defensa. Utilizando un marco analítico exhaustivo, este artículo revela que los actuales enfoques de rendición de cuentas dan prioridad a los consejos y los donantes, y ofrecen escasos informes a las comunidades pese a que las ONG se esfuerzan en asegurar lo contrario. En este artículo se recomienda desarrollar los mecanismos de rendimiento de cuentas gestionados por los organismos de coordinación de las ONG y centrados básicamente en la presentación de esas cuentas a las comunidades con el fin de mejorar los resultados de las ONG y protegerlas de ataques con motivaciones políticas.

Keywords NGO accountability - Community participation · Program evaluation · Organizational performance management · Organizational learning

\section{Introduction}

The success of NGOs over the last two decades in helping improve the lives of marginalized communities in developing countries through program and advocacy work is well recognized. However, the vocal advocacy of NGOs against governments, multilateral institutions, militant groups, and other stakeholders has also led to a strong backlash against them (Brown and Moore 2001). The backlash has consisted of cut-backs in funding; strict host government legislation; restrictions on operations; questioning of NGO performance, legitimacy and representativeness; physical attacks and calls for stronger NGO accountability (Jordan and Tuijl 2006; Naidoo 2004).

Many of the calls for greater NGO accountability genuinely aim to help them improve their performance based on evidence that actual NGO performance may not be as good as assumed. However, the calls from certain stakeholders are aimed 
mainly at muting NGO criticisms of their policies (Edwards 2006). The latter calls generally focus on upward accountability to donors and host governments and have the potential to distract attention from the importance that NGOs place on being accountable to communities (Fox and Brown 1998). Thus, more effective NGO accountability mechanisms will help both in enhancing their performance and protecting them from politically motivated attacks.

The main purpose of this article is to undertake an analysis of the main strengths and weaknesses of the current approaches to NGO accountability, especially with respect to the degree to which they emphasize accountability to communities and suggest ways for strengthening them. This analysis reveals that the accountability of NGOs is currently strongest to boards and donors and weakest to peer groups and communities. It also reveals that NGOs can best achieve the twin objectives of enhancing their own performance and protecting themselves from politically motivated attacks by voluntarily developing coordinated, peer-driven, and community-focused accountability mechanisms. The next section presents an analytical framework, developed through a thorough literature review, to understand and unpack the concept of NGO accountability. With the help of this framework, the third section analyzes the nature of accountability over NGOs that current approaches currently in use give different stakeholders. The final section provides recommendations for enhancing NGO accountability to communities. The ideas presented here are relevant for both international NGOs (those working in more than one developing country) and national NGOs.

\section{Accountability of NGOs: An Analytical Framework}

The calls for NGO accountability have grown louder recently due to several reasons. First, some stakeholders targeted by NGO advocacy have reciprocated by criticizing NGOs to undermine their credibility and advocacy activities. A key question being increasingly asked is "who do NGOs represent" as a way to undermining their legitimacy and weakening their ability to influence policies nationally and internationally. NGOs are criticized for having too much influence compared to their degree of representativeness and contribution (Naidoo 2004). Second, the explosive growth of NGOs has also made it easier for groups with ulterior motives to set up NGOs as fund-raising covers. For example, many militant groups have set up NGOs to collect funds for terrorist activities. This has led to the closer scrutiny of all NGOs in the wake of the 9/11 (McGann and Johnstone 2006; Bendell 2006). Many host governments and militants groups also perceive NGOs as working closely with the intelligence agencies of western countries while the former also view them as competitors for funding from western donors (Unerman and O’Dwyer 2006; Mayhew 2005).

Third, there have also been several high profile cases of abuse of power and resources involving even well-established NGOs, e.g., the client sexual abuse scandal in West Africa in the late 1990s (Jordan 2005, 2007; Bendell 2006). Fourth, several in-depth comparative evaluations of NGO projects have also raised 
questions about the quality of NGO projects (Riddell et al. 1997; Oakley 1999). These trends have reduced the trust surplus that NGO had enjoyed earlier. The growing realization that their good intentions alone may not necessarily translate into good results has led to increasing pressure on NGOs to provide evidence that they are performing well and using their funds transparently (Vibert 2007).

Thus, there are several advantages that can accrue to NGOs from voluntarily undertaking more effective accountability activities despite the extra costs. More effective accountability will enhance incentives for improved performance, encourage NGOs to become more closely aligned with community perspectives, and enhance shared learning about good practices and programs (Wenar 2006). It will provide greater assurance to donors and supporters, and help expand their support. It will also help achieve the morality and transparency considerations that NGOs strongly subscribe to by increasing their credibility and influence, and enhancing their ability to influence larger stakeholders to become more accountable (Sawarung 2003). By initiating more effective accountability mechanisms, NGOs can avoid the imposition of inappropriate and top-down accountability mechanisms by external stakeholders and protect themselves from politically motivated attacks (Wenar 2006; Unerman and O'Dwyer 2006).

Despite these benefits, the importance attached to accountability by NGOs varies significantly. In a study of over 600 NGOs globally, Scholte (2003) found that despite their emphasis on it in principle, most NGOs had given little practical attention to the issue. Accountability processes were seen as being too expensive and time-consuming, and adding little value to their work. Respondents felt that since the power of NGOs was limited compared to other agencies, their own accountability was not a serious issue. However, this argument misses the point that the accountability of agencies that advocate for the accountability of others is dictated primarily not by their size of contribution but by the strength of their advocacy. Calls for greater NGO accountability were also viewed with suspicion given the questionable motivation of many lobbyists and governments to use them as means for regulating NGOs. While these concerns do not reduce the rationale for NGO accountability, they do highlight the importance of ensuring that any new mechanism strengthens accountability to communities, does not impose exorbitant costs, provides real benefits in improving operations and avoids giving excessive authority to stakeholders with an "ax to grind" against NGOs. The following discussion aims to contribute to the achievement of these objectives by unpacking the concept of accountability (see Fig. 1).

In analyzing NGO accountability processes, the basic questions are: what does accountability really mean and what is its purpose? The literal meaning of accountability is the ability to take account from someone. Drawing upon the ideas provided by Schedler (1999) and Goetz and Jenkins (2002), this article defines accountability as the right to be involved in all phases and levels of the performance management cycle of an entity. This definition reflects the fact that beyond formal supervising individuals or entities, other stakeholders may also have the right to participate in the performance management process of an entity for a variety of purposes. The purpose of accountability is often viewed narrowly as identifying and punishing poor performance in light of stated goals only. However, the purposes of 


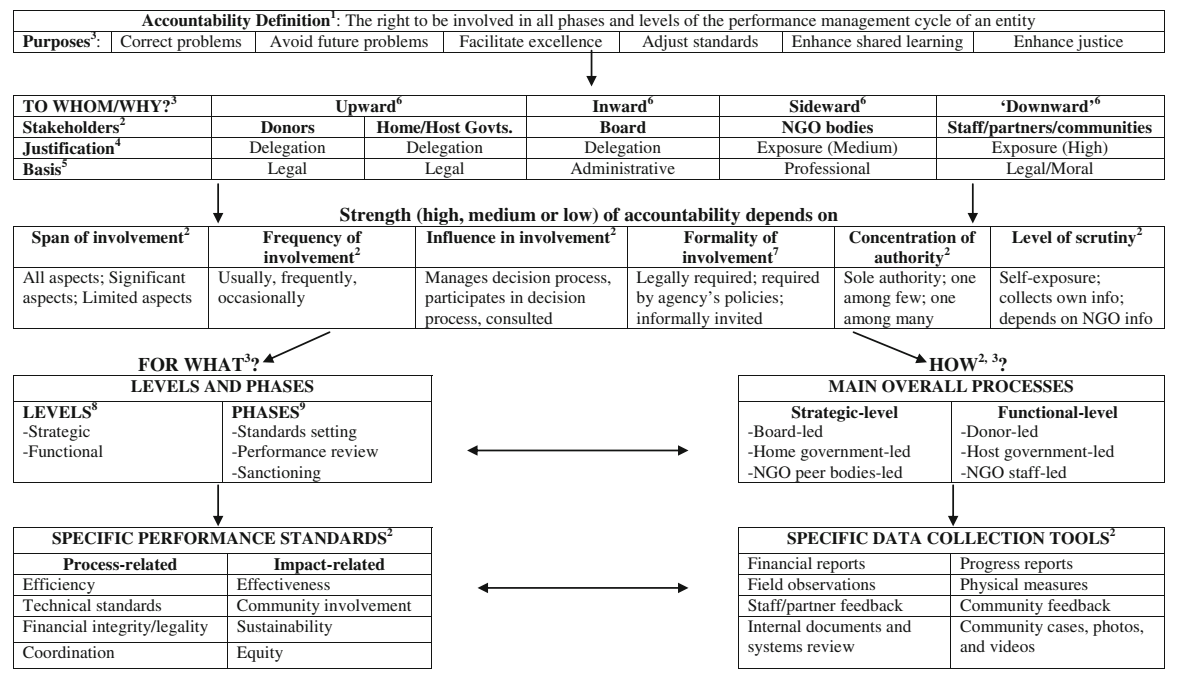

1. Adapted from Schedler (1999) and Goetz and Jenkins (2002); 2. Proposed by the current author; 3. Adapted from Lee (2004); 4. Grant and Keohane (2005); 5. Dwivedi, and Jabbra, (1988); 6. Adapted from Brown and Jagadananda (2007); 7. Adapted from Kilby, 2006); 8. Adapted from Cavill and Sohail (2007), Ebrahim (2003) and Edwards and Hulme (1995); 9. Adapted from Grant and Keohane (2005).

Fig. 1 NGO accountability—an analytical framework

accountability also include adjusting stated goals in line with a fluid environment, proactively avoiding poor performance, converting acceptable performance into excellence, enhancing shared learning among different stakeholders and most importantly, improving justice in access to power and resources (Adapted from Lee 2004).

Lee (2004) also identifies the following key questions to help develop NGO accountability frameworks: (1) To whom is the NGO accountable (to this, we add the question of "why")? (2) What is the NGO accountable for? (3) How is the NGO accountable? Grant and Keohane (2005) identify two sets of entities which are entitled to hold someone else to account: (1) those entities that have delegated authority or resources to another entity, and (2) those entities that are exposed to the effects of the actions of another entity. These two categories lead to several different types of accountability (Dwivedi and Jabbra 1988): (1) administrative (based on managerial oversight), (2) legal (based on contractual relationships and judicial authority), (3) moral (based on ethical values voluntarily accepted by an entity), (4) political (based on constituent relationships), and (5) professional (based on peer relationships with other similar professionals). To this can be added a sixth type of accountability that is based on the capacity of clients to withhold business, i.e., market accountability. The legal and administrative types lead to the strongest accountability relationships, the market and political basis lead to medium strength accountability relationships and professional and moral basis generally lead to relatively weak accountability relationships, as we discuss below.

Based on these concepts, a wide variety of stakeholders can claim accountability over NGOs, each one of them having very divergent aims in holding NGOs to account (Lloyd and de las Casas 2006; Brown and Jagananda 2007). International 
NGOs experience accountability in all four directions or $360^{\circ}$ accountabilityupward accountability to donors and home and host governments (legal basis with governments controlling the terms and conditions), inward accountability to their boards (administrative basis), "downward" accountability to communities (moral and in rare cases political and market basis), staff and partners (legal basis but with NGO controlling the terms and conditions), and sideward accountability to NGO bodies (professional basis). In addition, NGOs also have rather diffuse accountability to the general public (moral basis). The directional schema for accountability described above is commonly used by NGOs. Ironically, it aptly describes the hierarchical manner in which the various stakeholders are linked to NGOs in reality, with donors and governments above NGOs and communities, staff and partners below NGOs in the power hierarchy.

The strength of the accountability of these stakeholders varies significantly based on a variety of factors (Wapner 2002). First, the strength depends on the entity's span of involvement in the accountability process at a given level (see below for a description of the levels), which can range from all aspects, significant aspects and limited aspects (high, medium, and low span, respectively). For example, some entities may have the authority to set global standards in the area of human resources only (such as government labor relations departments) while another entity may have the ability to set global standards in all program and program support functions (such as the agency board). Second, the strength depends on how often an entity participates in NGO accountability, i.e., usually, frequently or occasionally (high, medium, and low frequency, respectively). Third, it depends on the degree of influence an entity has in NGO accountability processes, which can range from deciding alone/managing the decision-making process to participating in the decision-making process to being consulted during the decision-making process (high, medium, and low influence, respectively).

Fourth, the strength also depends on the level of formality of involvement (adapted from Kilby 2006), i.e., whether the participation of the entity is: (1) legally required, (2) administratively required by the accountable agency's board-mandated policies, or (3) at the informal discretion of the accountable agency's staff (high, medium, and low formality, respectively). Fifth, it depends on the level of concentration of authority in an entity. For example, boards and home governments are the sole authorities of their type for any NGO (high concentration). A donor, NGO body or host government is one among a limited number of its type and has significant capacity to coordinate with others of its type (medium concentration). Finally, a given community is usually one among a large number of communities that an NGO works with and has limited capacities to coordinate with other communities (low concentration). Finally, the strength depends on the level of scrutiny that an entity exercises over an $\mathrm{NGO}$, which varies from self-exposure (high scrutiny as in the case of communities) to usually collecting independent data about the NGO's performance (medium scrutiny) to usually relying on the information provided by the NGO or external auditors and evaluators hired by NGO staff members (low scrutiny).

The next question in the accountability of NGOs is "what is the accountability for?" The definition provided earlier helps in identifying three distinct phases of 
accountability, i.e., standards setting, performance appraisal and sanctioning, that an account-holder must participate into exercise effective accountability (Wenar 2006; Grant and Keohane 2005). However, in reality, account-holders, especially those in the case of NGOs, seldom possess a high degree of control in all of these phases (Charnovitz 2005). Another related aspect is the level of accountability. The two main levels of NGO accountability include functional/practical accountability (which refers to accountability for specific activities and projects) and strategic accountability (which focuses on accountability related to an agency's overall mission, goals, and policies) (adapted from Cavill and Sohail 2007; Ebrahim 2003b; Edwards and Hulme 1995). The final dimension of what an NGO is accountable for relates to the specific performance standards for NGOs, which consist of two types. The first type is impact oriented criteria: (1) involvement of communities, (2) effectiveness (e.g., high impact, timeliness, relevance, and convenience), (3) equity (for gender and other marginal groups), and (4) sustainability (environmental, financial, managerial, and political). The second type is process-oriented criteria: (5) technical standards, (6) financial integrity/legality, (7) efficiency (cost-benefit ratio), and (8) coordination with others.

The final question relates to how accountability is carried out. There is usually a tendency to equate "how" with the merits of specific data collection tools, such as participatory appraisal and social audits. However, the more important aspect of "how" from our point of view is the nature of the overall processes currently in use for undertaking accountability, which include: (1) board-managed global strategy planning and review, (2) NGO body accreditation/certification programs and codes of conduct, (3) home government registration and review, (4) donor-managed project approval, evaluation and audit, (5) host government NGO legislation and project approval, evaluation, and audit, and (6) NGO staff managed project cycle activities. The specific tools mainly used to collect data in these processes include: (1) financial data and reports, (2) narrative progress reports, (3) field observations, (4) physical measures, (5) staff/partner feedback through interviews and meetings, (6) community feedback through meetings, interviews and participatory exercises such as participatory rural appraisals or social audits, (7) internal documents and systems review, and (8) community stories, photos, and videos.

Thus, in light of the various criteria outlined above, the strongest accountability over NGOs will be exercised by an entity which participates at the strategic and functional levels in all three phases of NGO accountability with high frequency, span, influence, formality, scrutiny, and concentration of authority and is able to employ a wide range of performance criteria and data collection tools.

\section{An Overview of Current NGO Accountability Practices}

A number of approaches have been developed by different stakeholders for undertaking NGO accountability. These approaches include certification systems, rating systems, infrastructure and management capacity tools, self-regulation, codes of conduct, and monitoring and evaluation tools (Lee 2004). In addition to the lack of consensus on the merits of these approaches, they suffer from the following 
shortcomings (Jordan 2005): (1) give higher priority to accountability to donors and governments rather than communities, (2) are controlling rather than collaborative, (3) are disconnected from the reality and the context in which NGOs work, (4) include un-measurable or unrealistic goals, and (5) place heavy cost and time burden. This section analyzes these diverse processes, especially the extent to which they facilitate accountability to communities using the framework developed in the last section (see Table 1 for a summary).

\section{Processes for Strategic-Level NGO Accountability}

\section{Board-Led Accountability Processes}

The main NGO accountability process employed by boards is the board-led strategy development process, which generally sets out the overall mission, goals and plans of the agency, and its periodic reviews during which goals and plans are adjusted and action taken against the agency's senior management if performance falls significantly short of standards (Cornforth 2003). Boards generally rely on the information provided by NGO staff members and external auditors and evaluators hired by staff members and occasionally undertake field visits. Even so, an analysis in light of the evaluation framework criteria reveals that the strength of accountability that boards possess over NGOs is high as they participate in all three phases of NGO strategic accountability with high frequency, influence, span, and concentration of authority, medium formality, and low level of scrutiny.

For most agencies, the level of community participation in strategy development and review processes is limited and is usually at the discretion of international or field staff (low formality). Very few agencies, such as ActionAid, Oxfam and Save the Children, mandate such consultation as part of their board-approved accountability policies (medium formality). However, even in the case of these NGOs, communities are only consulted (low influence) about the standards and subsequent performance and are usually not involved in the sanctioning phase in case performance is not satisfactory (Wenar 2006). As its ultimate custodian, the main motivation for the board in agency accountability is safeguarding its reputation. The quality of services to communities is an important though not the only factor contributing to agency reputation (quality of marketing efforts is perhaps a more important contributing factor). Given the isolated nature of most NGO communities, the quality of program services must reach extremely low levels before there is a serious danger to agency reputation. Thus, the main incentive for the board is avoiding very poor program quality rather than converting ordinary performance into excellence.

\section{Home Government NGO Accountability Processes}

International NGOs face an additional process of accountability-the one managed by the home countries in which they are registered. The main NGO accountability process employed by home government NGO regulation authorities, such as the Charity Commission of England and Wales, is the NGO registration and subsequent 


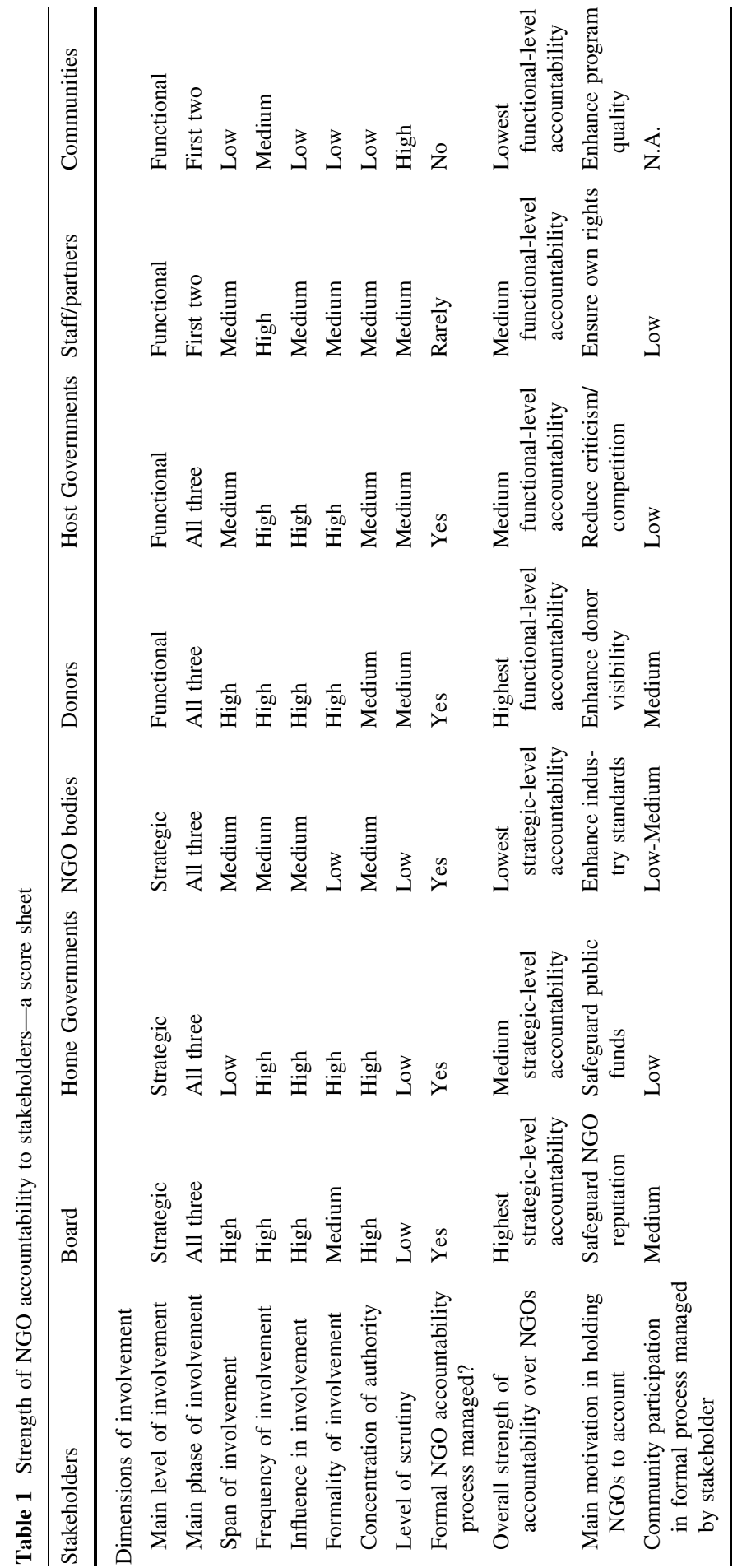


reporting mechanism. The Charity Commission of England and Wales has the authority to cancel the registration in case of wrong-doing by any NGO. The main motivation for it in NGO accountability is the protection of public funds collected by NGOs. Hence, the focus of its processes is mainly on financial and legal matters and they rarely look at the quality of operations and the extent of community participation (Charity Commission 2010). Since the bulk of the activities of INGOs are overseas, such departments generally have limited capacities to scrutinize NGO performance closely. Thus, viewed from the perspective of the evaluation framework criteria, home countries possess medium strength accountability over NGOs as they participate in all three phases of the accountability of NGOs at the strategic level with high frequency, influence, formality, and concentration of authority, and low span and level of scrutiny.

\section{NGO-Body Managed Accreditation Mechanisms}

The main NGO accountability process managed by NGO coordination or watchdog bodies are self-regulated accreditation mechanisms (Naidoo 2004). The main such mechanisms at the international level are: (1) the Red Cross NGO Codes of Conduct for emergencies, (2) the Sphere principles, (3) the Interaction self-regulation mechanism, (4) the One World Trust Global Accountability Project, (5) the ALNAP mechanism, (6) the Humanitarian Accountability Partnership, (7) the NGO Accountability Charter, and (8) the People in Aid mechanism. While the voluntary nature of NGO participation in these mechanisms limits their influence on NGO practices, reputational factors do encourage NGOs to enroll in these mechanisms, especially since many donors (e.g., the Australian government) consider participation in such mechanisms as one criterion in funding NGOs and approving taxexempt status. However, even if NGOs do enroll in them, most of them depend on self-reporting and very few mechanisms (e.g., the Philippine Council for NGO Certification) require third party assessment as a condition for certification. In a review of 35 such mechanisms, it was found that most such mechanisms focused on setting global industry standards for internal governance administration and financial management systems and the emphasis on community participation was generally weak (Lloyd and de las Casas 2006). Thus, even the most potent of these mechanisms possess medium strength accountability as they conduct accountability processes in all three phases at the strategic level with high influence (decide about giving accreditation), medium frequency (depending on the percentage of NGOs in a country enrolled in a particular mechanism), concentration authority and span and low formality and scrutiny capacity.

\section{Processes for Functional-Level NGO Accountability}

\section{Donor-Led NGO Accountability Process}

By pursuing funding from donors, NGOs make themselves accountable to donors for all three phases of accountability at the functional level (for particular projects and activities). First, they have to make sure that the goals for the project are in line with 
donor funding priorities. Second, based on contractual obligations, the donors also have the legal right to measure performance at the end of the project. Finally, at the sanctioning phase, the donor has the authority not only to refuse future funding if it is not satisfied with performance but also to ask for the money back on the current project if the money has not been used according to the terms and conditions of the contract. The main tools employed by donors for NGO accountability are the proposal approval and project evaluation processes. A few donors (e.g., the Swedish government) also have formal accreditation processes before NGO become eligible to submit proposals to them. Very few donors manage the evaluation and audit process themselves or through external evaluators and auditors appointed by them (e.g., the USAID appoints its own auditors for large projects). Their assessment is generally based on the progress, financial, and audit reports submitted by the NGO, supplemented in some cases by field visits by donor staff members (ACCA 2009). Thus, the level of scrutiny experienced by the NGO during the performance evaluation phase varies significantly.

However, overall, the strength of donor accountability over NGOs is high as donors participate in NGO accountability process in all three phases at the functional level with high frequency, influence, span and formality and medium scrutiny capacity and concentration of authority. The overall span of a donor at the total functional level of an agency depends on the percentage of the agency's global project funds that come from it. This could be very high if an agency is primarily dependent on one donor, such as in the case of many large American NGOs and US government funding. In such cases, the sum of the functional accountability of the donor across all projects may translate into high strategic accountability for the donor over the NGO, since the NGO may be forced to close down globally if the donor stops funding it. On the other hand, many large British NGOs generally put limits on how much funding they receive from one donor or even all donors and invest significant efforts in raising funds from the general public. This helps to limit donor influence on their policies at the strategic level. However, it may also mean that no external stakeholder has strong accountability powers over such NGOs.

In reviewing proposals and actual performance, almost all donors do give significant weight to whether the agency has involved communities in the needs assessments, project implementation, and project evaluation phases. Donor staff and evaluators usually obtain feedback from communities during field visits about their satisfaction with the project design and implementation. However, the actual level of emphasis is generally at the discretion of individual staff members (low formality). In addition, donor reporting requirement rigidities reduce program effectiveness and divert attention away from community realities and requirements (ACCA 2009; Ebrahim 2003a). The main incentive for donors in funding projects in developing countries is enhancing positive donor visibility. Thus, the donor's main focus in accountability, as with boards, is on avoiding major problems in projects funded by it rather than encouraging excellence in services to communities.

\section{Host Government-Managed NGO Accountability Processes}

The main accountability process employed by host governments is the NGO legislation, registration, and subsequent reporting process. There has been a 
significant increase in the number of host countries adopting strict processes for the accountability of NGOs as the level of advocacy and funding of NGOs has increased. The governmental attitude in developing NGO legislation ranges from a strong desire for control to apathy, depending on whether relationships with NGOs are cordial or tense (Mayhew 2005). The legislation normally describes the behavior expected of NGOs in running operations, designing projects and regular reporting. With respect to sanctioning, governments usually attempt to control NGO behavior through delays in or refusals of project approvals, work visas for expatriates, and travel and import permits, and in rare cases, governments can even expel NGOs. As in the case of donors, the level of scrutiny experienced by NGOs depends on the strength of the monitoring mechanisms adopted by different governments. Only in rare cases do governments undertake independent evaluations of NGO activities. Overall, the strength of host governments' accountability over NGOs is high as they participate in all three phases of NGO accountability at the functional level with high influence, frequency and formality, and medium span, level of scrutiny, and concentration of powers. Rarely is there any strong emphasis in host governmentled NGO accountability processes on ensuring community participation and accountability as the main focus of host governments is reducing the criticism and competition from NGOs.

\section{NGO Staff Managed Accountability Processes}

The most common process for setting standards and measuring performance for projects and activities at the functional level are NGO-managed needs assessments, project evaluations and audits. However, the quality of these assessments and evaluations vary significantly, especially the latter since there is a strong bias for reporting positive results among all stakeholders even when the evaluations are done by NGO-recruited external stakeholders. NGO staff members prefer positive evaluations to impress internal and external stakeholders, communities are reluctant to make overly critical remarks and risk losing NGO project support and external evaluators have an interest in maintaining good relationships so that they get work in future (Wenar 2006). Major meta-studies of NGO effectiveness have found achievements but also major problems with the quality of NGO evaluation processes, especially about the use of vague objectives, the lack of baseline data and the poor quality of outcomes data collected that make it difficult to evaluate the impact of NGOs (Evison 1999; Riddell et al. 1997; Oakley 1999). These problems are magnified by the problems associated with the criteria and data collection tools used in the development sector, as explained below.

NGOs generally collect community perceptions during the needs assessments, proposal design, and project evaluation stages. However, community participation in such processes is generally through group meetings or individual interviews where decision-making power is retained by project staff-a process referred to as "sham ritual" or feel-good exercises for both participants and NGOs by Najam (1996). Ebrahim (2003b) argues that for true accountability, it is crucial that communities are able to negotiate and bargain over decisions or even hold veto powers. Such powers are not afforded even under highly participatory exercises, 
such as social audits and Participatory Rural Appraisals. Thus, given the fact that NGO-managed processes are frequently the main sources of information for the accountability processes managed by other stakeholders, NGOs enjoy a very high degree of control over their own accountability processes. Where donors and governments play a more active role, NGOs do get exposed to more external scrutiny. However, that greater scrutiny may not necessarily lead to improvements in quality of services to communities depending on the basic motivation of the external stakeholder.

\section{Issues with the Performance Criteria and the Tools}

NGO accountability is also complicated by the fact that NGOs do not have a simple bottom-line, such as annual profits in the case of corporations (Gray et al. 2006). While a number of criteria have been developed for measuring NGO performance (listed in the last section), most of them relate not to strategic-level agency performance but to performance of individual NGO projects (functional level accountability). These is little attempt or easy techniques available to integrate the individual functional performance analysis into overall strategic level performance analysis. In addition, each of the functional level criteria is complex and difficult to measure, and requires a wide range of information covering demographic, financial, economic political, cultural, physical, psychological, and environmental areas. This requires the use of several of the tools mentioned above, many of which are timeconsuming and expensive to use, and have variable validity and reliability, especially since NGO projects usually takes place in isolated areas lacking good communication and logistics facilities. Some NGO activities and their impact are easier to measure, especially those involving delivery of discrete materials, such as food, water, and shelter. However, others are more difficult to track and measure, such as capacity-building and advocacy activities (Davies 2002). Furthermore, there is very little investment in standardization of these criteria their measurement or of the specific data collection tools. Nor do current NGO record-keeping patterns allow the easy measurement and comparison of these criteria across time, territory, and agencies. These issues with the performance criteria and tools reduce the scrutiny capacities of all stakeholders.

The analysis above reveals an interesting picture about the nature of NGO accountability. At the strategic level, the strongest accountability is to boards and the weakest accountability to NGO bodies, with home governments falling in between. At the functional level, donors and host governments possess high and medium strength accountability, respectively, staff and partners possess medium strength accountability while communities have weak accountability. In addition, stakeholders that possess a high degree of strategic-level accountability over NGOs generally exercise low levels of scrutiny. Donors and host governments generally employ higher levels of scrutiny but exercise accountability mainly at the functional level. Thus, even though boards exercise the strongest accountability powers over NGOs this power is diluted in practice by the low level of scrutiny exercised usually by them. As such, no stakeholder scores high across the board on all the criteria presented above. 
The two stakeholders with the weakest accountability powers are peers and communities. In particular, communities exercise the lowest level of accountability among all stakeholders even in the case of the most community-oriented NGOs despite strong rhetoric to the contrary (Kilby 2006; Mulgan 2003; Najam 1996; Salamon et al. 2000). In fact, even the common use by NGOs of the term "downward accountability" to refer to accountability to communities aptly describes where in the hierarchy communities fall for NGOs. Communities possess high scrutiny capacities based on personal exposure but generally participate only in the first two phases (no involvement in the sanctioning process) of functional accountability processes with low influence, formality, span, and concentration of authority and medium frequency. Unlike other stakeholders, they do not manage a formal NGO accountability process and their participation is through the formal processes managed by other stakeholders and at the latter's discretion. These stakeholders generally focus on avoiding extremely poor services to communities rather than on encouraging excellence in program quality. Not surprisingly, several studies have questioned the quality of NGO programs (Evison 1999; Riddell et al. 1997; Oakley 1999). As such, current processes focus on the first four purposes of accountability and do not help in converting acceptable performance into excellence and in ensuring greater justice in the global economy and polity.

However, if accountability is to live up to its real purpose, i.e., improving justice in the use of the world's power and resources, then it is crucial that NGOs purposefully strengthen their "downward" accountability in order to convert acceptable performance into excellence and to ensure greater justice in the global economy and polity. In addition, the stakeholders who frequently criticize NGOs base it (at least overtly even though the real motivations may be self-serving) mainly on the supposed lack of representativeness and accountability of NGOs to communities and their own supposed accountability or at least high degree of concern for communities. Thus, NGOs can simultaneously improve their performance and protect themselves better against politically motivated accountability calls by voluntarily developing processes that foster strong and genuine accountability to communities and gaining wide-spread acceptance for such processes among all stakeholders, including donors and governments. This wide-spread acceptance can best be gained by developing these processes collectively with peers in NGO coordination bodies, such as HAP, ALNAP and Interaction, rather than individually.

A large number of peer-managed accreditation processes were identified earlier which generally participate in all three phases of NGO strategic accountability with high influence, medium frequency, concentration authority and span, and low formality and scrutiny capacity. The effectiveness of these mechanisms can be enhanced by increasing their: (1) frequency, span and formality of involvement (2) concentration authority, (3) scrutiny capacities, and (4) reach to the functional level. These attributes can be enhanced by increasing coordination among different peer mechanisms, getting a larger number of donors, home-governments and NGOs onboard and through the development of standardized and more easily measurable performance criteria and valid, reliable and cost-effective data collection tools. NGO accountability mechanisms must also ensure high community accountability over NGOs by increasing the frequency, formality, influence, span, concentration of 
authority, and scrutiny powers of community involvement in all three phases of NGO accountability at both the strategic and functional levels. For example, this can be done by helping community-based organizations to federate at the regional and national levels and having their representatives participate in NGO accountability and project evaluation processes, and, where feasible, even having them on NGO boards. Thus, paradoxically, by enhancing the accountability powers of its two weakest stakeholders, NGOs can protect themselves against politically motivated pressures from more powerful stakeholders.

\section{Conclusions}

This article has provided a comprehensive framework for developing a better understanding of the concept of NGO accountability and its various dimensions. The analysis has clearly shown that, despite the rhetoric to the contrary, NGO accountability is weakest to the communities and strongest to the board and donors. This situation has provided the opportunity to politically motivated parties to question the legitimacy and integrity of NGOs. At the same time, research by wellintentioned parties has also shown significant problems with the program evaluation processes employed by NGOs. Thus, there is a need to seriously reconsider current approaches to NGO accountability that lack rigor, quality, objectivity, and cohesiveness and do not help much in achieving the two most important purposes of accountability: converting acceptable performance into excellence and ensuring greater justice in the global economy and polity.

The article has essentially argued for strengthening the accountability of NGOs to communities through coordinated accreditation programs managed by NGO coordinating bodies with the active support of donors, home governments, and other stakeholders. Clearly, this will involve greater external intrusion into the operations of NGOs. However, as agencies fighting for transparency in society, NGOs should embrace such intrusion in their own affairs whole-heartedly given that the process outlined here empowers those two stakeholders most that NGOs have the least to be suspicious about. Only by doing so would NGOs follow Chambers' inspiring call to put the last first.

Open Access This article is distributed under the terms of the Creative Commons Attribution Noncommercial License which permits any noncommercial use, distribution, and reproduction in any medium, provided the original author(s) and source are credited.

\section{References}

ACCA. (2009). NGO accountability and aid delivery. Glasgow: The Association of Chartered Certified Accountants.

Bendell, J. (2006). Debating NGO accountability. New York: United Nations Non-Governmental Liaison (NGLS).

Brown, L., \& Jagananda, K., (2007). Civil society legitimacy and accountability: Issues and challenges, Working Paper No. 32, The Hauser Center for Nonprofit Organizations, The John F. Kennedy School of Government, Harvard University, Boston, MA. 
Brown, L., \& Moore, M. (2001). Accountability, strategy, and international Non-Governmental Organizations. Nonprofit and Voluntary Sector Quarterly, 30, 569-587.

Cavill, S., \& Sohail, M. (2007). Increasing strategic accountability: A framework for international NGOs. Development in Practice, 17(2), 231-248.

Charity Commission. (2010). Charity Commission Annual Report 2009-2010, Charity Commission for England and Wales, London, UK.

Charnovitz, S. (2005). Accountability of Nongovernmental Organizations (NGOs) in global governance, Public Law and Legal Theory Working Paper no. 145, The George Washington University Law School, Washington, DC.

Cornforth, C. (2003). The Governance of Public and Non-Profit Organizations: What Do Boards Do? London: Routledge.

Davies, R. (2002). Monitoring and evaluating NGO achievements. In V. Desai \& B. P. Robert (Eds.), The companion to development studies. Arnold; New York: Oxford University Press.

Dwivedi, O., \& Jabbra, J. (1988). Public service responsibility and accountability. In J. G. Jabbra \& O. Dwivedi (Eds.), Public service accountability: A comparative perspective. Hartford, CT: Kumarian Press.

Ebrahim, A. (2003a). NGOs and Organizational Change. Cambridge: Cambridge University Press.

Ebrahim, A. (2003b). Accountability in practice: Mechanisms for NGOs. World Development, 31(5), 813-829.

Edwards, M. (2006). Foreword. In L. Jordan \& P. V. Tuijl (Eds.), NGO accountability: Politics, principles and innovations. London: Earthscan.

Edwards, M., \& Hulme, D. (1995). Beyond the magic bullet: NGO accountability and performance. London: Earthscan.

Evison, I. (1999). Learning from evaluations in Christian Aid: A critical analysis of evaluation reports 1991-98. London: Christian Aid.

Fox, J. A., \& Brown, D. (1998). Accountability within transnational coalitions. In J. A. Fox \& D. L. Brown (Eds.), The struggle for accountability: The World Bank, NGOs and grassroots movements. Cambridge, MA: MIT Press.

Goetz, A. M., \& Jenkins, R. (2002). Voice, accountability and development: The emergence of a new agenda, Human Development Report 2002, New York: UNDP.

Grant, R., \& Keohane, R. (2005). Accountability and abuses of power in world politics. American Political Science Review, 99, 29-43.

Gray, R., Bebbington, J., \& Collison, D. (2006). NGOs, civil society and accountability: Making the people accountable to capital. Accounting, Auditing \& Accountability Journal, 19(3), 319-348.

Jordan, L. (2005). Mechanisms for NGO Accountability. GPPI Research Paper Series No.3, Global Public Policy Institute, Berlin, Germany.

Jordan, L. (2007). A rights-based approach to accountability. In A. Ebrahim \& E. Weisband (Eds.), Global accountabilities and moral community: Civil society organizations and multilateral institutions. Cambridge University Press: New York.

Jordan, \& Tuijl, P. (2006). Rights and responsibilities in the political landscape of NGO accountability. In L. Jordan \& P. Tuijl (Eds.), NGO accountability: Politics, principles and innovations. London: Earthscan.

Kilby, P. (2006). Accountability for Empowerment: Dilemmas facing Non-Governmental Organizations. World Development, 34(6), 951-963.

Lee, J. (2004). NGO accountability: Rights and responsibilities, Programme on NGOs and Civil Society, CASIN, Geneva, Switzerland.

Lloyd, R., \& de las Casas, L., (2006). NGO self-regulation: Enforcing and balancing accountability, One World Trust, London, UK. www.oneworldtrust.org.

Mayhew, S. (2005). Hegemony, politics and ideology: The role of legislation in NGO-Government Relations in Asia. Journal of Development Studies, 41(5), 727-758.

McGann, J., \& Johnstone, M. (2006). The power shift and the NGO credibility crisis. The International Journal of Not-for-Profit Law, 8(2), 65-77.

Mulgan, R. (2003). Holding power to account: Accountability in modern democracies. New York: Palgrave MacMillan.

Naidoo, K. (2004). The end of blind faith? Civil society and the challenge of accountability, legitimacy and transparency. AccountAbility Forum, 2, 14-25.

Najam, A. (1996). NGO accountability: A conceptual framework. Development Policy Review, 14(4), 39-353. 
Oakley, P. (1999). Overview report: The Danish NGO impact study. A review of Danish NGO activities in developing countries. Oxford: INTRAC.

Riddell, R. C., Kruse, S.-E., Kyollen, T., Ojanpera, S., \& Vielajus, J.-L. (1997). Searching for impact and methods: NGO evaluation synthesis study. A report produced for the OECD/DAC Expert group on evaluation. Helsinki: Department for International Development Cooperation, Ministry of Foreign Affairs.

Salamon, L. M., Hems, L. C., \& Chinnock, K. (2000). The non-profit sector: For what and for whom? Working papers of the Johns Hopkins comparative non-profit sector project, no. 37. Baltimore.

Sawarung. (2003). Workshop Summary Report: Protecting the rights and addressing the responsibilities of Non-Governmental Organizations, Sawarung, Bandung, Indonesia, 6-8 January 2003.

Schedler, A. (1999). Conceptualizing accountability. In A. Schedler, L. Diamond, \& M. F. Plattner (Eds.), The self-restraining state: Power and accountability in new democracies. London: Lynne Rienner Publishers.

Scholte, J. (2003). Protecting the rights and addressing the responsibilities of Non-governmental Organisations, Unpublished paper, Warwick University, Coventry, UK.

Unerman, J., \& O'Dwyer, B. (2006). On James Bond and the importance of NGO accountability. Accounting, Auditing \& Accountability Journal, 19(3), 305-318.

Vibert, F. (2007). NGO codes of conduct: Monitored self-regulation?. London: European Policy Forum. Wapner, P. (2002). Defending accountability in NGOs. Chicago Journal of International Law, 3(1), $197-205$.

Wenar, L. (2006). Accountability in international development aid. Ethics \& International Affairs, 20(1), $1-23$. 